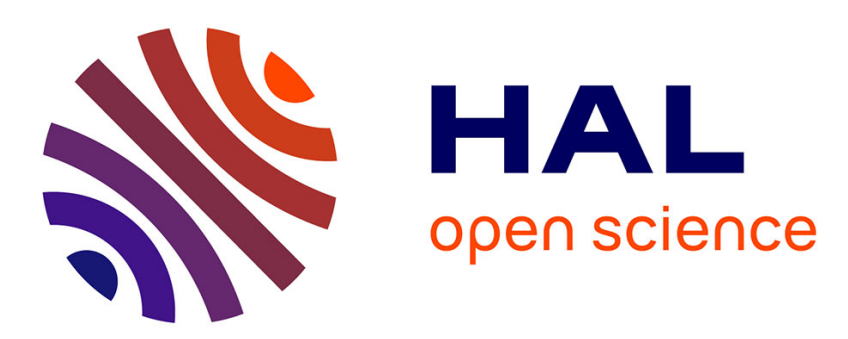

\title{
Aptitude de l'espèce Penicillium Caseicolum à la production d'enzymes protéolytiques
}

\author{
J. Lenoir, C. Choisy, B. Auberger, J. Marrasse, M. Schmidt
}

\section{To cite this version:}

J. Lenoir, C. Choisy, B. Auberger, J. Marrasse, M. Schmidt. Aptitude de l'espèce Penicillium Caseicolum à la production d'enzymes protéolytiques. Le Lait, 1971, 51 (503_504), pp.138-157. hal00928542

\section{HAL Id: hal-00928542 \\ https://hal.science/hal-00928542}

Submitted on 1 Jan 1971

HAL is a multi-disciplinary open access archive for the deposit and dissemination of scientific research documents, whether they are published or not. The documents may come from teaching and research institutions in France or abroad, or from public or private research centers.
L'archive ouverte pluridisciplinaire HAL, est destinée au dépôt et à la diffusion de documents scientifiques de niveau recherche, publiés ou non, émanant des établissements d'enseignement et de recherche français ou étrangers, des laboratoires publics ou privés. 


\title{
Aptitude de l'espèce Penicillium Caseicolum à la production d'enzymes protéolytiques ${ }^{(1)}$
}

\author{
par \\ J. LENOIR et C. CHOISY \\ avec la collaboration technique de \\ B. AUBERGER, J. MARRASSE et M. SCHMIDT \\ Laboratoire de Technologie \\ Ecole Nationale Supérieure Agronomique de Grignon (78)
}

\section{SOMMAIRE}

L'aptitude de Penicillium caseicolum à la production de protéases a été éprouvée sur une centaine de souches de diverses origines par ensemencement en milieux liquides contenant de l'azote nitrique ou de l'azote peptidique.

Pour l'ensemble des souches la croissance et la production d'enzymes protéolytiques sont notablement plus élevées en présence de la forme d'azote organique. Sur chacun des milieux les résultats obtenus sont relativement groupés. Ainsi, les activités protéasiques sur le milieu contenant de l'azote peptidique se situent dans un intervalle dont l'amplitude de variation est voisine de 1 à 2 . Par son aptitude à la production d'enzymes protéolytiques la population étudiée présente donc une grande homogénéité.

\section{INTRODUCTION}

Dans les fabrications de fromages à pâte molle et à croûte moisie deux espèces de moisissures sont ensemencées : Penicillium caseicolum Bainier (syn. P. candidum Link) et Penicillium camemberti Thom (syn. P. album Preuss). Les deux espèces sont d'ailleurs

(1) Travail réalisé dans le cadre d'un Contrat de la Délégation Générale à la Recherche Scientifique et Technique, Contrat $n^{\circ} 6701037$, sur l'emploi d'enzymes d'origine microbienne dans l'affinage des fromages. 
très proches. Elles appartiennent l'une et l'autre à la section des Penicillia asymétriques non divergents, groupe Lanata caractérisé par l'apparence touffue et laineuse du mycélium. Elle se distinguent par l'aspect des colonies qui restent de couleur blanche ou crème dans le cas de $P$. caseicolum ou qui deviennent gris-vert pâle pour $P$. camemberti lors de la formation des conidies (Raper et Thom, 1949 ; Sakaguchi et Abe, 1957). Actuellement, l'espèce P. caseicolum est, sinon la seule, du moins la plus couramment ensemencée en fabrications fromagères ; elle présente l'avantage de recouvrir le fromage d'un feutrage d'une parfaite blancheur (Desfleurs, 1966).

L'activité protéolytique de $P$. caseicolum est depuis longtemps reconnue (Maze, 1905 ; Thom, 1906 ; Dox, 1908 ; Thom, 1909 ; Sansonnetti, 1930) et un certain nombre de travaux relativement récents ont cherché à préciser l'importance et la nature de cette activité.

Dolezalek (1956) étudie l'action de la moisissure par culture sur un milieu nutritif additionné de caséine ; il observe une protéolyse maximale à la température de $15^{\circ} \mathrm{C}$, protéolyse caractérisée par la libération d'une proportion importante d'acides aminés. Par une méthode de culture identique Proks et Cingrosova (1962) comparent les activités de $P$. caseicolum et de $P$. camemberti. Leurs résultats confirment les caractères de protéolyse relevés par Dolezalek : une activité peptidasique élevée et la libération d'une petite proportion d'ammoniac, indice d'une faible activité désaminasique. Tsugo et Matsuoka (1963) mettent en évidence la production de trois enzymes protéolytiques dont les $\mathrm{pH}$ d'activité optimale sont respectivement $3,0-6,8$ et 10,5 ; la protéase neutre, relativement thermostable et peu sensible au sel, serait naturellement celle qui est susceptible d'intervenir le plus efficacement dans la maturation des diverses pâtes r fromagères.

Il reste, toutefois, que les études réalisées ont porté sur un petit nombre de souches. Il n'est donc pas certain qu'elles reflètent les caractères de l'espèce $P$. caseicolum prise dans son ensemble et, par suite, elles ne permettent pas de préciser l'aptitude réelle de celle-ci à la protéolyse. Aussi nous a-t-il paru nécessaire, avant d'aborder une étude systématique des conditions de production des enzymes protéolytiques et des caractères de leur activité, de déterminer, sur une collection de souches de diverses origines, les aptitudes à la production de protéases.

\section{PROTOCOLE EXPERIMENTAL}

\section{1) Constitution d'une collection de souches}

Des isolements ont été effectués, à diverses époques, sur des échantillons de fromages fermiers ou industriels de différents types (Camembert, Brie, Carré de l'Est, Neufchâtel...) sur des murs de 
caves d'affinage, sur des suspensions commerciales de spores. Une collection d'une centaine de souches a été ainsi constituée.

A cette collection, ont été ajoutées des souches mises à notre disposition par deux autres laboratoires : le Laboratoire de Microbiologie de la Faculté des Sciences de Caen et le Laboratoire de la Société Lacto-Labo.

Sur un ensemble de plus de 150 souches, caractérisées par examen des colonies et observation au microscope des conidiophores, 108 souches de $P$. caseicolum et 8 souches appartenant à des espèces voisines ont été finalement retenues pour l'étude de l'aptitude à la production de protéases.

\section{2) Conditions de culture}

Chaque souche est ensemencée sur deux ou, le plus souvent, trois composition suivante : néopeptone (Difco) $10 \mathrm{~g}$; glucose $20 \mathrm{~g}$; phosphate dipotassique $7,5 \mathrm{~g}$; caséine Hammarsten (NBC) $20 \mathrm{~g}$; ealı q.s.p. 11 - pH 7,0. La souche est ensuite ensemencée en tube à essai sur une pâte constituée d'un mélange de farine de seigle et de blé. Après $10 \mathrm{j}$ d'incubation à $18-20^{\circ} \mathrm{C}$ les spores sont récoltées par agitation en présence de $10 \mathrm{ml}$ de solution de Ringer au 1/4.

La richesse de la suspension de spores est estimée par mesure de la densité optique à $650 \mathrm{~m} \mu$ et les lectures photométriques sont traduites en nombre de spores à l'aide d'une courbe d'étalonnage établie par dénombrement au microscope.

La suspension est diluée au taux convenable et le milieu de culture inoculé par addition de $1 \mathrm{ml}$ de suspension à $40 \mathrm{ml}$ de milieu, le taux d'ensemencement étant 10000 spores par $\mathrm{ml}$ de milieu.

Deux milieux de culture ont été utilisés : le milieu de CzapekDox modifié et le milieu " Czapek-trypticase ». Le milieu de CzapekDox (Thom et Raper, 1945) a été modifié par apport de glucose, supplémentation en oligo-éléments et addition d'un tampon phosphate. Il a la composition suivante : glucose $10 \mathrm{~g} ; \mathrm{Na} \mathrm{NO}_{3} 3 \mathrm{~g} ; \mathrm{Mg} \mathrm{SO}_{*}$, $7 \mathrm{H}_{2} \mathrm{O} 0,5 \mathrm{~g} ; \mathrm{KCl} 0,5 \mathrm{~g}$; $\mathrm{Fe} \mathrm{SO}_{4}, 7 \mathrm{H}_{2} \mathrm{O} 0,01 \mathrm{~g}$; solution d'oligoéléments $10 \mathrm{ml}$; eau distillée $500 \mathrm{ml}$; tampon phosphate $\mathrm{pH} 6,5$ $0,2 \mathrm{M} 500 \mathrm{ml} ; \mathrm{pH}$ final 6,5.

La solution aqueuse d'oligo-éléments contient pour $100 \mathrm{ml}$ : $\mathrm{Cu} \mathrm{Cl} 215,5 \mathrm{mg} ; \mathrm{Zn} \mathrm{SO}_{4}, 7 \mathrm{H}_{2} \mathrm{O} 175,6 \mathrm{mg} ; \mathrm{Mn} \mathrm{Cl}_{2}, 4 \mathrm{H}_{2} \mathrm{O} 36 \mathrm{mg}$; $\mathrm{Ca} \mathrm{Cl}_{2} 2 \mathrm{H}_{2} \mathrm{O} 183,4 \mathrm{mg}$; $\left(\mathrm{NH}_{4}\right) 6 \mathrm{Mo}_{7} \mathrm{O}_{24}, 4 \mathrm{H}_{2} \mathrm{O}$ 10,2 mg (Meyers et Knight, 1958).

Le milieu "Czapek-trypticase » a la même composition que le précédent à l'exception de la source d'azote, le nitrate de sodium étant remplacé par une peptone trypsique de caséine, la trypticase (Mérieux) au taux de $10 \mathrm{~g}$ par 1. 
Les milieux de culture sont répartis en erlenmeyers de $150 \mathrm{ml}$, à raison de $40 \mathrm{ml}$ par erlenmeyer, et stérilisés par autoclavage à $115^{\circ} \mathrm{C}$ pendant $20 \mathrm{mn}$.

Chaque souche est ensemencée sur deux ou, le plus souvent trois fioles coniques pour chacun des deux milieux et les fioles sont mises à l'étuve à $20^{\circ} \mathrm{C}$ pendant $12 \mathrm{j}$, sans agitation. 20 à 25 souches sont éprouvées simultanément et l'étude de la collection a été effectuée en six séries d'essais.

\section{3) Détermination de l'activité protéasique}

\subsection{Préparations enzymatiques}

Après incubation, le milieu de culture est filtré sur papier de qualité filtration courante et centrifugé à 5000 tours mn pendant $10 \mathrm{mn}$. Le $\mathrm{pH}$ est mesuré par potentiométrie et ajusté, si nécessaire, à $\mathrm{pH}$ 6,0 par addition de quelques gouttes de solution d'acide sulfurique environ $\mathrm{N}$. Le liquide obtenu constitue la préparation enzymatique extracellulaire.

Le mycélium séparé par filtration est lavé à l'eau puis égoutté et pesé. Sur une partie aliquote, la teneur en matière sèche du mycélium est déterminée par dessiccation à $102^{\circ} \mathrm{C}$ pendant $15 \mathrm{~h}$. Un poids donné de mycélium frais (à $10-12$ p. 100 de matière sèche) est additionné d'une quantité de tampon phosphate $0,066 \mathrm{M}, \mathrm{pH} 6,0$ correspondant à $20 \mathrm{ml}$ pour $1 \mathrm{~g}$ de mycélium sec. Le broyage du mycélium est effectué avec l'appareil de Braun (type 2876) en flacon de $75 \mathrm{ml}$ en présence de $50 \mathrm{~g}$ de billes de verre de $1 \mathrm{~mm}$ de diamètre; le temps de broyage est de $2 \mathrm{mn}$ à la vitesse maximum de l'appareil et le mélange est maintenu à basse température par refroidissement à l'aide d'anhydride carbonique liquide.

Le broyat obtenu est amené au volume de $100 \mathrm{ml}$ par g de mycélium sec par addition de tampon phosphate $0,066 \mathrm{M}$ et la suspension, conservée $30 \mathrm{mn}$ à température ambiante, est centrifugée $10 \mathrm{mn}$ à 5000 tours $/ \mathrm{mn}$. Le surnageant constitue la préparation enzymatique intracellulaire.

\subsection{Conditions de digestion}

L'activité protéolytique des préparations est déterminée sur un substrat à base de caséine : caséine Hammarsten (NBC) $25 \mathrm{~g}$, citrate de sodium 0,02 M q.s.p. $1000 \mathrm{ml}, \mathrm{pH}$ ajusté à 7,0 par addition de soude environ $\mathrm{N}$. Le substrat est stérilisé $20 \mathrm{mn}$ à $120^{\circ} \mathrm{C}$ et, avant emploi, additionné de merthiolate à la dose de $50 \mu \mathrm{g}$ par $\mathrm{ml}$.

Les mélanges de digestion ont la composition suivante :

- Caséinate de sodium à 2,5 p. $100 \ldots \ldots$. . . . . . . 2,5 ml

- Tampon mixte (acétate-borate-phosphate $0,25 \mathrm{M}, \mathrm{pH} 6$ ). . 0,5 ml

- Préparation enzymatique intra ou extracellulaire .. . . . $1 \mathrm{ml}$

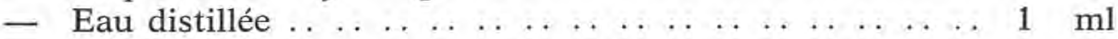


La digestion est conduite en tubes à essai placés en bain-marie thermostaté à la température de $40^{\circ} \mathrm{C}$, pendant $2 \mathrm{~h}$.

\subsection{Mesure de l'activité enzymatique}

Le mélange de digestion est déféqué par addition de $5 \mathrm{ml}$ d'acide trichloracétique à 24 p. 100 et sur le filtrat trichloracétique, les composés azotés non protéiques sont dosés par colorimétrie selon Folin et Ciocalteu (1927). A $1 \mathrm{ml}$ de filtrat sont ajoutés : 6,5 ml d'eau, $2 \mathrm{ml}$ de solution de carbonate de sodium à $150 \mathrm{~g}$ par $1,0,5 \mathrm{ml}$ de réactif de Folin. La lecture photométrique est faite, après maintien $5 \mathrm{~h}$ à la température ambiante, à la longueur d'onde de $770 \mathrm{~m} \mu$ avec un spectrophotomètre Beckman DU.

Les mélanges de digestion non incubés, sont traités dans les mêmes conditions.

Les lectures photométriques sont traduites en poids de tyrosine à l'aide d'une courbe d'étalonnage. Les résultats, exprimés en $\mu \mathrm{g}$ de tyrosine libérée par $\mathrm{ml}$ de préparation et par heure de digestion, concrétisent l'activité protéasique.

\section{RESULTATS}

\section{Mise au point des conditions opératoires}

1.1. Les conditions de détermination de l'activité enzymatique ont été précisées au cours d'essais préliminaires qui ont été réalisés sur deux souches. Ont été notamment déterminées l'influence de la quantité d'enzymes, du temps, de la température et du $\mathrm{pH}$ de digestion.

1.1.1. L'influence de la quantité d'enzymes a été estimée en faisant varier les volumes de préparation enzymatique dans les limites 0-2 $\mathrm{ml}$, avec une température de digestion de $40^{\circ} \mathrm{C}$, un $\mathrm{pH}$ de mélange 6,5 , les temps de digestion étant de $5 \mathrm{~h}$ pour les préparations intracellulaires, $2 \mathrm{~h}$ pour les préparations extracellulaires. On observe, dans ces limites, des degrés de protéolyse pratiquement proportionnels aux quantités d'enzymes (fig. 1).

1.1.2. L'influence du temps de digestion a été déterminée dans l'intervalle $0-7 \mathrm{~h}$, à la température de $40^{\circ} \mathrm{C}$, un $\mathrm{pH}$ de 6,5 et une quantité d'enzymes de $1 \mathrm{ml}$. Les résultats obtenus montrent qu'il existe un rapport direct entre la quantité de tyrosine libérée et le temps de digestion lorsque celui-ci est compris entre 0 et $2 \mathrm{~h}$ (fig 2 ).

1.1.3. L'influence de la température de digestion a été estimée dans l'intervalle $30-50^{\circ} \mathrm{C}$ avec des volumes de préparation enzymatique de $1 \mathrm{ml}$ (préparation intracellulaire) et $2 \mathrm{ml}$ (préparation extracellulaire), un temps de digestion de $5 \mathrm{~h}$, un $\mathrm{pH}$ du mélange de 6,5. 
Les résultats obtenus mettent en évidence une température optimale proche de $45-50^{\circ} \mathrm{C}$ (fig. 3 ). Les activités intra et extracellulaires ne semblent cependant pas présenter les mêmes sensibilités aux variations de température. Pour une augmentation de température de $10^{\circ} \mathrm{C}$, dans l'intervalle $30-40^{\circ} \mathrm{C}$, l'activité intracellulaire est approximativement doublée, l'activité extracellulaire est multipliée par le coefficient 1,5 .

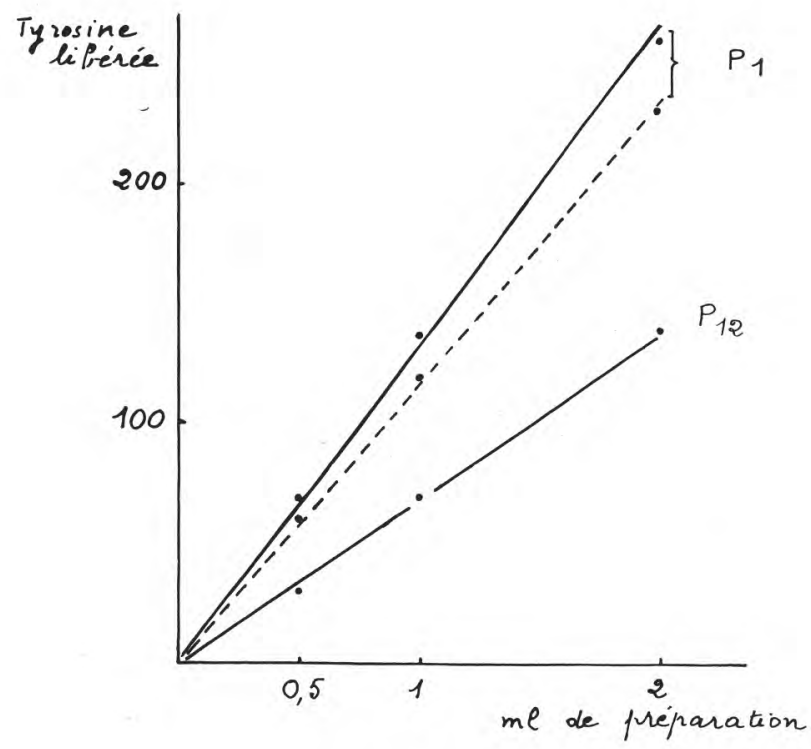

fig. 1

Influence de la quantité d'enzymes sur le degré de protéolyse du substrat par $P$. caseicolum

- En abscisses, le volume de préparation enzymatique en ml.

- En ordonnées, le degré de protéolyse exprimé en $\mu \mathrm{g}$ de tyrosine libérée en $1 \mathrm{~h}$ de digestion.

Trait plein : enzymes extracellulaires.

Tiret : enzymes intracellulaires.

Conditions des essais :

- Culture : milieu Czapek-trypticase, incubation $12 \mathrm{j}$ à $18^{\circ} \mathrm{C}$, $\mathrm{pH} \mathrm{6,} \mathrm{sans} \mathrm{agitation.}$

- Détermination des activités : temps de digestion $2 \mathrm{~h}$ pour des enzymes extracellulaires, $5 \mathrm{~h}$ pour les enzymes intracellulaires, température $40^{\circ} \mathrm{C}, \mathrm{pH} 6,5$. 
1.1.4. L'influence $d u p H$ a été déterminée dans l'intervalle de $\mathrm{pH}$ 4-8 en introduisant dans les mélanges de digestion un tampon mixte acétate-borate-phosphate ajusté à $\mathrm{pH}$ convenable. Les conditions des essais ont été les suivantes : volume de préparation enzymatique de $1 \mathrm{ml}$ (préparation intracellulaire) et $2 \mathrm{ml}$ (préparation extracellulaire), temps de digestion $5 \mathrm{~h}$, température de digestion $40^{\circ} \mathrm{C}$.

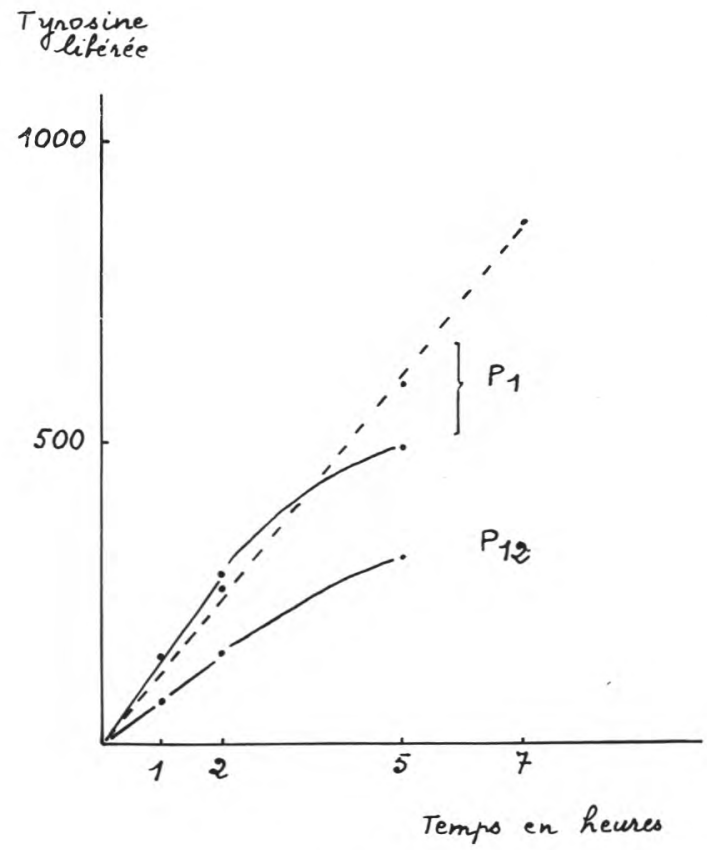

fig 2

Influence du temps de digestion sur le degré de protéolyse du substrat par les enzymes de $P$. caseicolum

- En abscisses, le temps de digestion en heures.

- en ordonnées, le degré de protéolyse exprimé en $\mu \mathrm{g}$ de tyrosine libérée par $\mathrm{ml}$ de préparation.

Trait plein : enzymes extracellulaires.

Tiret : enzymes intracellulaires.

Conditions des essais :

- Culture : milieu Czapek-trypticase, incubation $12 \mathrm{j}$ à $18^{\circ} \mathrm{C}$, $\mathrm{pH} \mathrm{6,} \mathrm{sans} \mathrm{agitation.}$

- Détermination des activités : volume de préparation $1 \mathrm{ml}$, température $40^{\circ} \mathrm{C}, \mathrm{pH} 6,5$. 
On observe, pour les deux préparations, un $\mathrm{pH}$ optimal voisin de 6 et des variations d'activité de faible amplitude dans la zone de $\mathrm{pH}$ 5,5-6,5 (fig. 4).

1.2. Les conditions de culture favorables à la croissance de la moisissure et à la production des enzymes protéolytiques ont été également recherchées sur deux souches témoins. L'influence des facteurs suivants a été notamment étudiée : la composition du

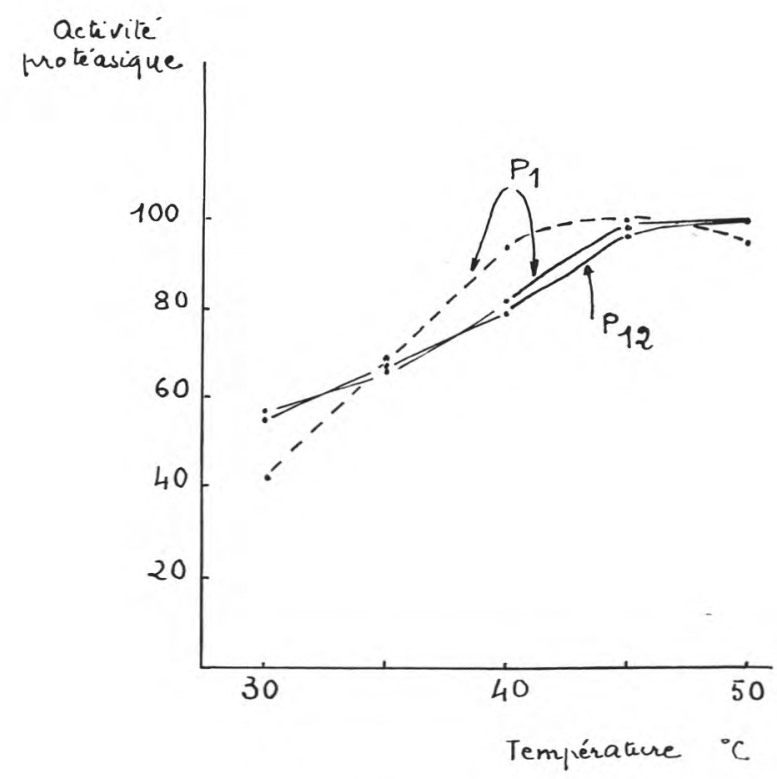

fig 3

Influence de la température sur l'activité protéasique de $P$. caseicolum

- En abscisses, les températures en degrés Celsius.

- En ordonnées, l'activité protéasique exprimée en p. 100 de l'activité optimale.

Trait plein : activité extracellulaire.

Tiret : activité intracellulaire.

Conditions des essais :

- Culture : milieu Czapek-trypticase, incubation $12 \mathrm{j}$ à $18^{\circ} \mathrm{C}$, $\mathrm{pH}$ 6, sans agitation.

- Détermination de l'activité : volume de préparation $2 \mathrm{ml}$ (extracellulaire), $1 \mathrm{ml}$ (intracellulaire), temps de digestion $5 \mathrm{~h}, \mathrm{pH} 6,5$. 
milieu (nutrition azotée, carbonée, minérale, vitaminique), l'agitation et l'aération, le $\mathrm{pH}$ du milieu, la température d'incubation... Les résultats de cette étude feront l'objet d'une prochaine publication. Nous noterons simplement que la présence dans le milieu d'azote peptidique, une certaine teneur en oligo-éléments, une concentration saline assez élevée, une zone de $\mathrm{pH}$ 5,5-7,0, des températures de culture de $18-25^{\circ} \mathrm{C}$ sont favorables à la croissance et à la production d'enzymes.

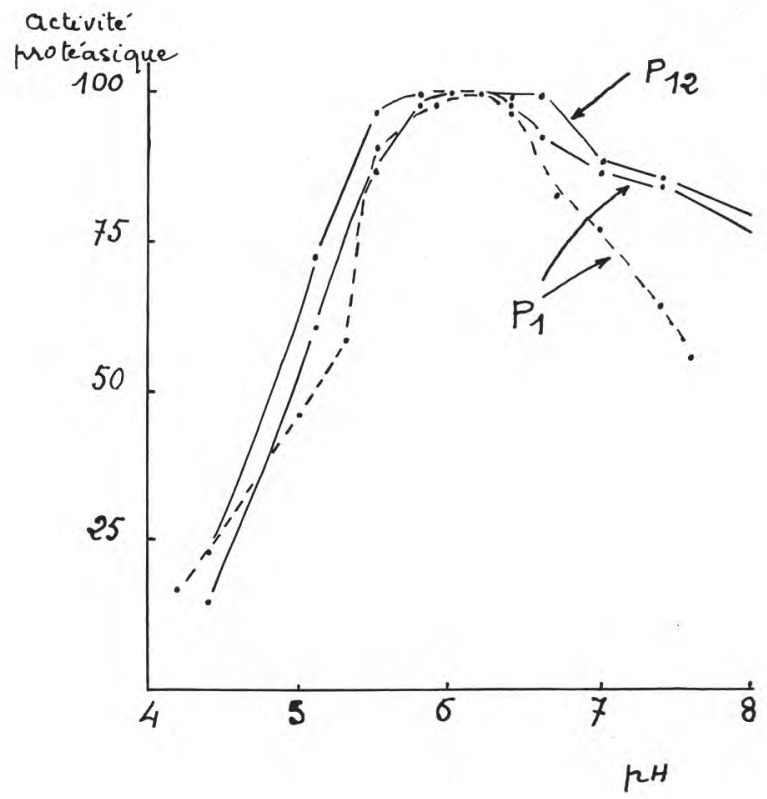

fig 4

Influence du $\mathrm{pH}$ sur l'activité protéasique de $P$. caseicolum

- En abscisses, pH du mélange de digestion.

- En ordonnées, activité protéasique exprimée en p. 100 de l'activité optimale.

Trait plein : activité extracellulaire.

Tiret : activité intracellulaire.

Conditions des essais :

- Culture : milieu Czapek-trypticase, incubation $12 \mathrm{j}$ à $18^{\circ} \mathrm{C}$, $\mathrm{pH} 6$, sans agitation.

- Détermination des activités : volumes de préparation $2 \mathrm{ml}$ (extracellulaire) ou $1 \mathrm{ml}$ (intracellulaire), temps de digestion $5 \mathrm{~h}$, température $40^{\circ} \mathrm{C}$. 
En ce qui concerne les temps de culture, il apparaît qu'en milieu non agité, mais avec une répartition assurant un large contact avec l'air, et à une température de $18-20^{\circ} \mathrm{C}$, le développement du mycélium et la production d'enzymes extracellulaires s'amorcent après le $6^{\mathrm{me}} \mathrm{j}$. Les accroissements de poids et d'activité sont particulièrement nets entre le $10^{\mathrm{me}}$ et le $12^{\mathrm{me}} \mathrm{j}$. Par la suite, une diminution du poids de mycélium est observée en raison sans doute d'une certaine autolyse qui pourrait être à l'origine de l'augmentation complémentaire de l'activité protéasique constatée sur le filtrat de culture (fig. 5).

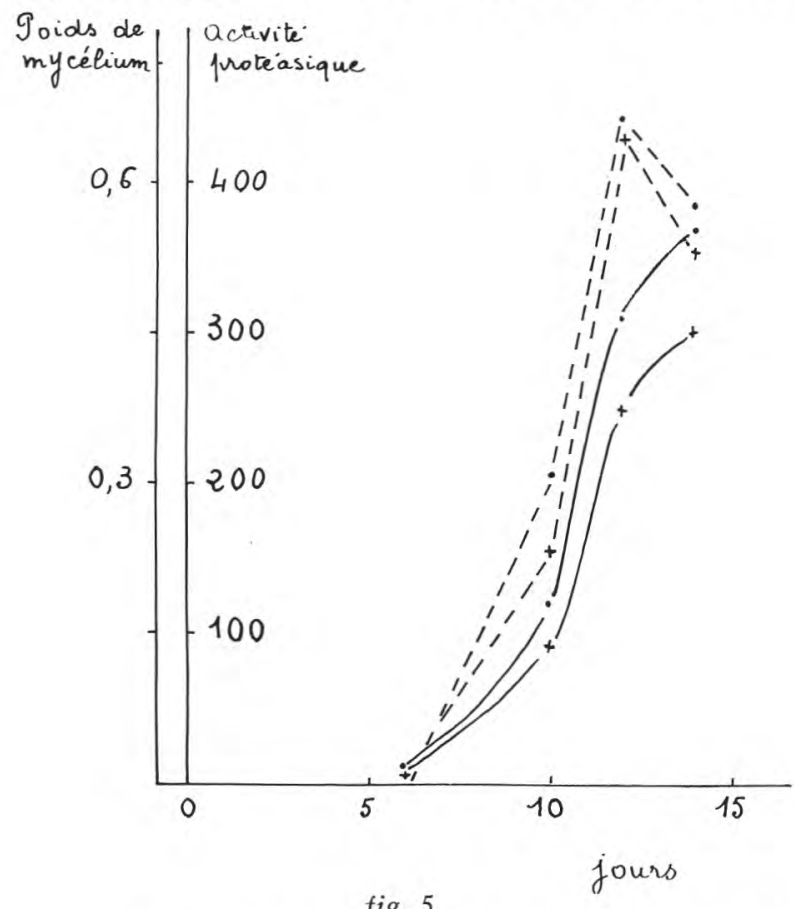

Croissance du mycélium et production de protéases extracellulaires par $P$. caseicolum

- En abscisses, le temps d'incubation en jours.

- En ordonnées, les poids de mycélium en g pour $100 \mathrm{ml}$ de milieu et les activités protéasiques en $\mu \mathrm{g}$ de tyrosine libérée par $\mathrm{ml}$ de préparation en $5 \mathrm{~h}$.

Trait plein : activités protéasiques.

Tiret : poids de mycélium.

$\bullet \quad$ : souche $\mathrm{P} 1$ 1.

++ : souches P 12 .

Conditions de culture :

- Milieu Czapek-trypticase réparti en erlenmeyer de $150 \mathrm{ml}$ à raison de $40 \mathrm{ml}$ par fiole, incubation $18^{\circ} \mathrm{C}$, sans agitation.

Conditions de détermination de l'activité protéasique :

- Volume de préparation $2 \mathrm{ml}$, temps de digestion $5 \mathrm{~h}$, température $40^{\circ} \mathrm{C}, \mathrm{pH}$ du mélange 6,5 . 


\section{TABLEAU 1}

Reproductibilité des résultats de la détermination de l'activité protéasique*

(Activité exprimée en $\mu \mathrm{g}$ de tyrosine libérée par $\mathrm{ml}$ de préparation enzymatique et par heure)

a) Reproductibilité dans une même série d'essais

(Résultats des trois essais obtenus avec les dix premières souches de la série II).

\begin{tabular}{c|c}
\hline Numéro des souches & Activités \\
\cline { 2 - 2 } & \\
PL 1 & $320-340-355$ \\
PL 2 & $340-330-335$ \\
PL 3 & $335-325-325$ \\
PL 4 & $290-295-300$ \\
PL 5 & $360-345-340$ \\
PL 6 & $230-210-195$ \\
PL 7 & $315-320-320$ \\
PL 8 & $365-335-360$ \\
PL 9 & $260-280-275$ \\
PL 10 & $250-235-250$ \\
\hline
\end{tabular}

b) Reproductibilité dans les séries différentes

\begin{tabular}{|c|c|c|c|c|c|c|}
\hline \multirow{2}{*}{$\begin{array}{c}\text { Souches } \\
n^{\circ}\end{array}$} & \multicolumn{6}{|c|}{ Activités moyennes dans les séries $\mathrm{n}^{\circ}$} \\
\hline & 1 & 2 & 3 & 4 & 5 & 6 \\
\hline & 320 & & 300 & 290 & 320 & 280 \\
\hline $\mathrm{P} \quad 12$ & 225 & & 220 & & & \\
\hline PL 19 & & 375 & 340 & 385 & & \\
\hline PL 23 & & 295 & 260 & & & \\
\hline PA 14 & & & 295 & 260 & & \\
\hline P 16 & 110 & & & & 155 & 150 \\
\hline PL 21 & & 440 & & & 400 & 350 \\
\hline
\end{tabular}

\section{* Conditions des essais}

Culture sur milieu Czapek-trypticase, $\mathrm{pH}$ 6,5, incubation $12 \mathrm{j}$ à $20^{\circ} \mathrm{C}$ sans agitation, ensemencement sur trois erlenmeyers par souche.

Activité protéasique extracellulaire déterminée sur $1 \mathrm{ml}$ de préparation, temps de digestion $2 \mathrm{~h}$, température $40^{\circ} \mathrm{C}, \mathrm{pH} 6,0$. 


\section{$2^{\circ}$ Croissance et activité protéasique des souches de la collection}

Sur les cultures obtenues (soit, pour une souche, deux ou trois erlenmeyers pour chacun des deux milieux) sont déterminés, après incubation $12 \mathrm{j}$ à $20^{\circ} \mathrm{C}$, le $\mathrm{pH}$ final du milieu, le poids du mycélium sec et l'activité protéasique extracellulaire. Avec le mycélium récolté à partir des cultures en milieu Czapek-trypticase, l'activité protéasique intracellulaire est également déterminée.

Dans les conditions de développement mises en œuvre, la croissance du mycélium, la production d'enzymes et l'évolution du $\mathrm{pH}$ de la culture présentent une reproductibilité satisfaisante dans une même série d'essais ainsi que d'une série d'essais à l'autre (tab.1). Les résultats moyens d'une souche peuvent donc être considérés comme significatifs et une comparaison peut être faite entre les souches éprouvées dans une même série d'essais (tab. 1 a). Pour les souches éprouvées dans des séries d'essais différentes, les variations observées sont assez faibles (tab. 1 b) ; il en a cependant été tenu compte et une correction a été appliquée aux résultats des séries 1-2-4-5 et 6, la série 3 ayant été prise comme témoin.

Les résultats obtenus sur les deux milieux sont représentés sur les histogrammes des figures 6,7 et 8 .

Avec le milieu de Czapek-Dox, le pH final des cultures oscille entre 6,2 et 6,8 , le poids de mycélium, en g pour $100 \mathrm{ml}$ de milieu, de 0,17 à 0,47 , l'activité protéasique extracellulaire exprimée en $\mu \mathrm{g}$ de tyrosine libérée par $\mathrm{ml}$ de préparation et par heure de digestion de 20 à 225.

Avec le milieu Czapek-trypticase le $\mathrm{pH}$ final de culture est compris entre 6,8 et 7,3 , le poids de mycélium de 0,47 à 1,05 , l'activité protéasique extracellulaire de 210 à 450, l'activité intracellulaire de 60 à 230.

\section{DISCUSSION}

La comparaison des résultats obtenus sur milieu de Czapek-Dox et sur milieu Czapek-trypticase fait clairement apparaître une différence importante entre les deux milieux de culture. Cette différence est observée aussi bien pour les poids de mycélium que pour les activités enzymatiques extracellulaires. Avec le milieu Czapek-trypticase (C T), la croissance mycélienne et la production d'enzymes sont nettement plus grandes qu'avec le milieu Czapek-Dox modifié (C D). Ainsi, les poids de mycélium moyens sont respectivement 0,63 et $0,34 \mathrm{~g}$ pour $100 \mathrm{ml}$ de milieu, les activités protéasiques extracellulaires 310 et 90 . Les différences entre les deux milieux sont donc sensiblement plus importantes pour ce qui concerne la production d'enzymes que pour la croissance du mycélium, les rapports moyens respectifs C T/C D étant voisins de 3,5 et 1,9. Par ailleurs, on observe, d'une souche à l'autre, des différences notables de comportement ; 


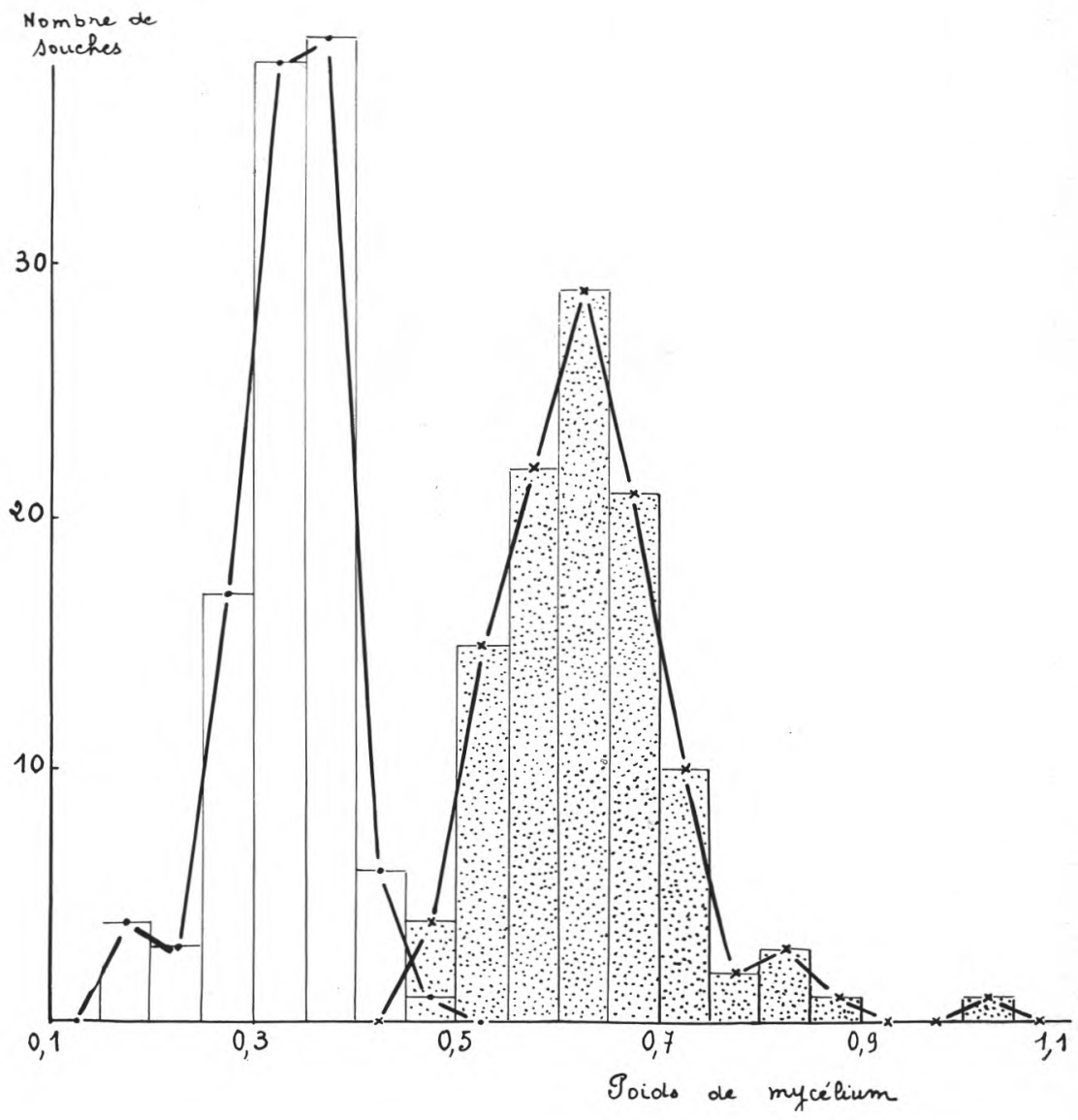

fig 6

Distribution des souches de $P$. caseicolum en fonction du poids de mycélium

- En abscisses, les classes de poids, poids exprimés en g p. $100 \mathrm{ml}$ de milieu.

- En ordonnées, le nombre des souches appartenant aux différentes classes.

La partie claire correspond aux résultats obtenus avec le milieu de Czapek-Dox, la partie mouchetée à ceux obtenus avec le milieu Czapek-trypticase. 


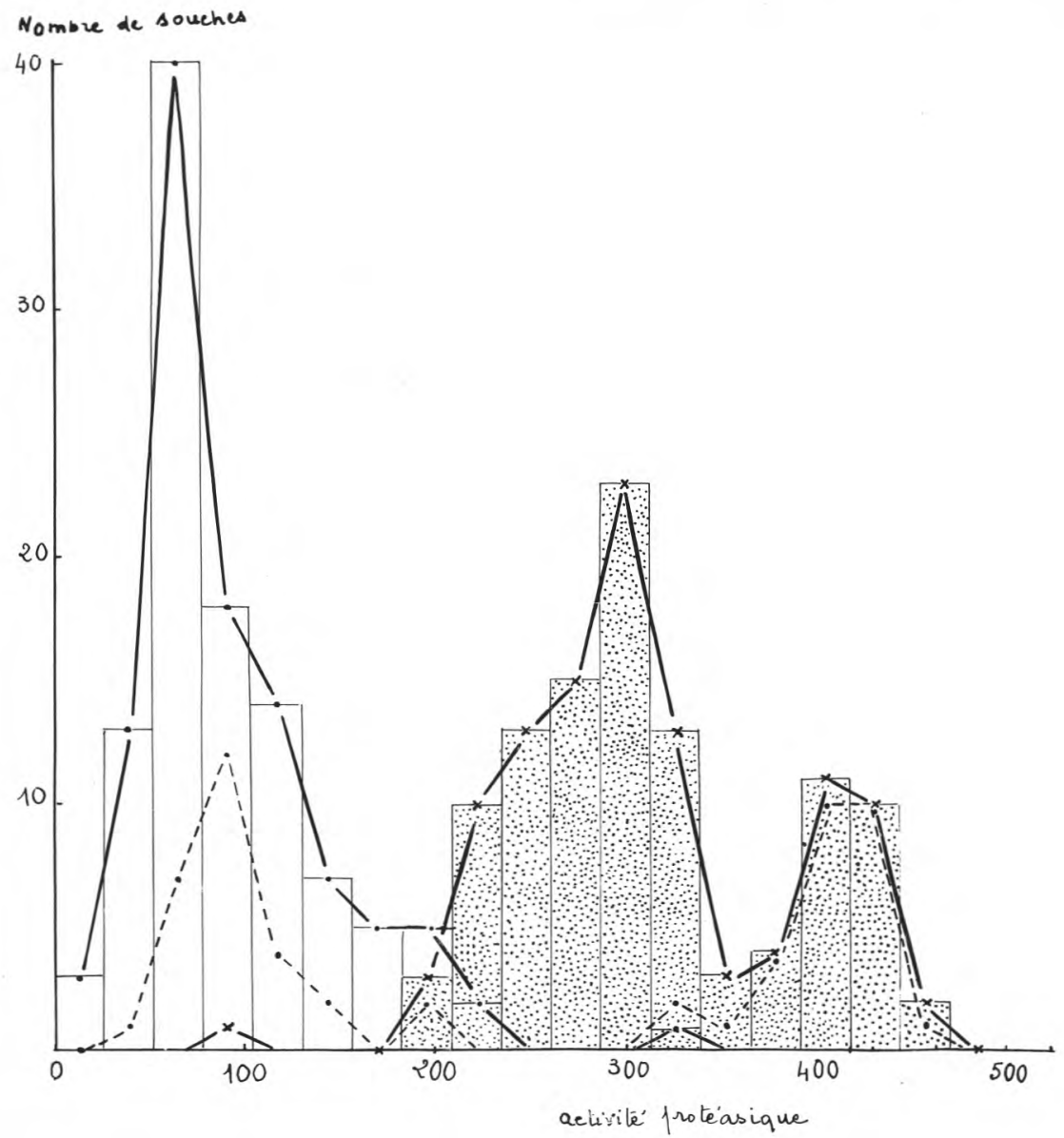

fig. 7

Distribution des souches de $P$. caseicolum en fonction de leur activité protéasique extracellulaire

- En abscisses, les classes d'activité protéasique, activité exprimée en $\mu \mathrm{g}$ de tyrosine libérée par $\mathrm{ml}$ de préparation et par heure de digestion.

- En ordonnées, le nombre de souches appartenant aux différentes classes.

La partie claire correspond aux résultats obtenus avec le milieu de Czapek-Dox, la partie mouchetée correspond à ceux obtenus avec le milieu Czapek-trypticase.

Les lignes en pointillé, représentent la distribution des souches d'origine Neufchâtel. 
Nombre de souches

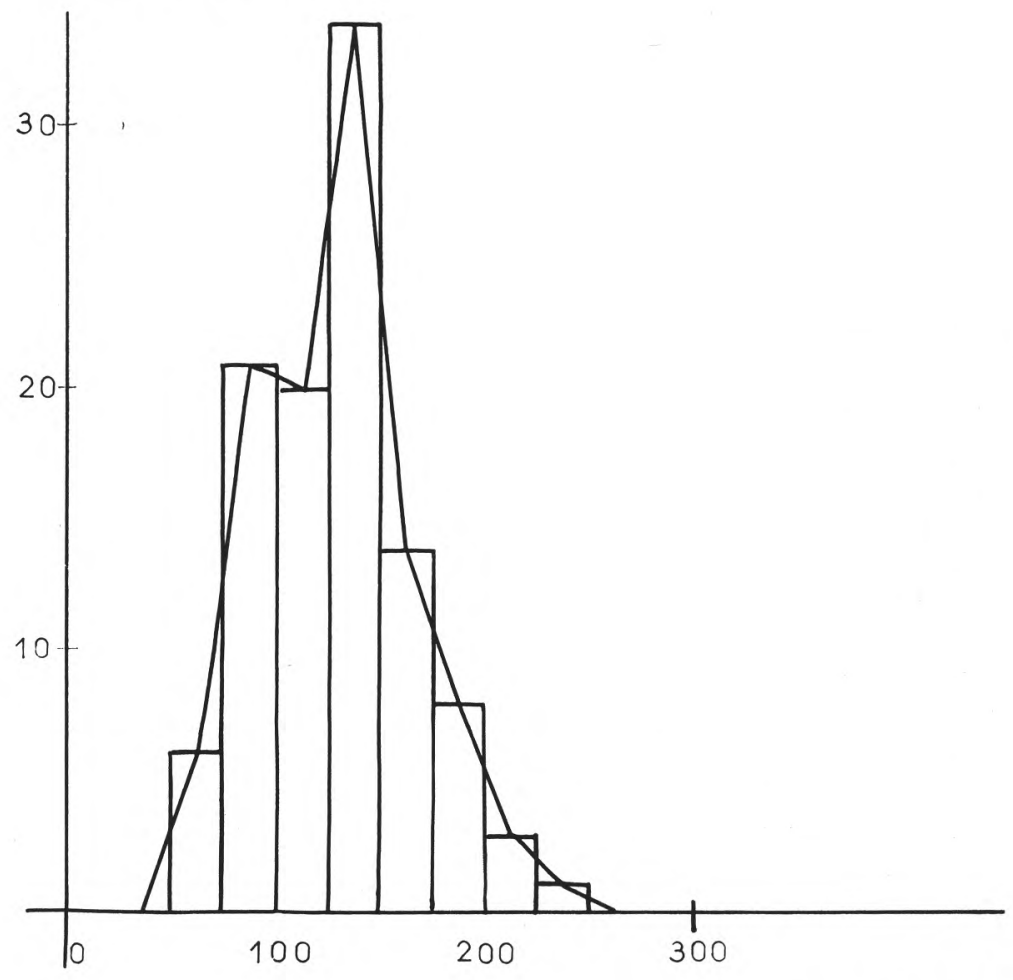

Activité protéasique

fig. 8

Distribution des souches de $P$. caseicolum en fonction de leur activité protéasique intracellulaire

- En abscisses, les classes d'activité, activité exprimée en $\mu \mathrm{g}$ de tyrosine libérée par $\mathrm{ml}$ de préparation et par heure de digestion.

- En ordonnées, le nombre de souches appartenant aux différentes classes. 
TABLEAU 2

a) Classement des souches de $P$. caseicolum en fonction de leur aptitude à la production de protéases.

\begin{tabular}{|c|c|c|c|c|}
\hline \multirow{2}{*}{ Groupes $\mathrm{n}^{\circ}$} & \multicolumn{2}{|c|}{ Sur milieu Czapek-Dox } & \multicolumn{2}{|c|}{ Sur milieu Czapek-trypticase } \\
\hline & $\begin{array}{l}\text { Classes } \\
\text { d'activité }\end{array}$ & $\begin{array}{l}\text { Nombre de } \\
\text { souches }\end{array}$ & $\begin{array}{l}\text { Classes } \\
\text { d'activité }\end{array}$ & $\begin{array}{l}\text { Nombre de } \\
\text { souches }\end{array}$ \\
\hline 1 & $<26$ & 3 & $<186$ & 1 \\
\hline 2 & $26-52$ & 13 & $186-238$ & 13 \\
\hline 3 & $53-79$ & 40 & 239-291 & 30 \\
\hline 4 & $80-106$ & 18 & 292-344 & 33 \\
\hline 5 & 107-159 & 21 & $345-397$ & 11 \\
\hline 6 & $160-238$ & 13 & $398-476$ & 20 \\
\hline
\end{tabular}

b) Différence de classement des souches sur l'un et l'autre milieu.

\begin{tabular}{c|c}
\hline Note différentielle* & Nombre de souches correspondant \\
\cline { 2 - 2 } 0 & 21 \\
1 & 53 \\
2 & 22 \\
4 & 10 \\
& 2 \\
\hline
\end{tabular}

* La note différentielle correspond au numéro de groupe sur un milieu moins le numéro de groupe sur l'autre. 
le rapport des activités protéasiques extracellulaires C T/C D oscille en effet entre les valeurs 1,5 et 6 et les classements des souches en fonction de leur aptitude à la production d'enzymes sur les deux milieux ne sont pas concordants (tab. 2). Deux conclusions peuvent être tirées de ces observations.

La production d'enzymes ne semble pas directement liée à la croissance mycélienne et, selon les souches, l'influence de la source d'azote sur la synthèse des protéases peut être plus ou moins déterminante.

Les résultats concernant l'ensemble des souches, pour chacun des deux milieux de culture, sont relativement homogènes. Ainsi, avec le milieu Czapek-Trypticase, les poids de mycélium récoltés après $12 \mathrm{j}$ d'incubation sont, pour la plupart, compris entre 0,5 et $0,75 \mathrm{~g}$ (fig. 6) et les $\mathrm{pH}$ des cultures oscillent entre 6,8 et 7,3 . Les productions d'enzymes observées sur ce milieu varient aussi dans des limites assez étroites ; elles ne débordent guère l'intervalle 210-450, soit une amplitude de variation voisine de 1 à 2 . Toutefois, la courbe de répartition des souches en fonction de leur activité protéasique (fig. 7) présente les caractéristiques d'une distribution de type bimodal, près des $3 / 4$ des souches se situant dans l'intervalle 210-320, environ $1 / 4$ dans l'intervalle 350-450. Une telle forme de distribution peut être considérée comme l'indice de l'existence de deux sous-groupes au sein de la population étudiée. L'hypothèse apparaît d'autant plus vraisemblable que presque toutes les souches d'origine Neufchâtel se retrouvent dans le sous-groupe le plus activement protéolytique et que, à elles seules, elles constituent l'essentiel de ce sous-groupe.

Avec le milieu de Czapek-Dox l'amplitude des variations concernant la production d'enzymes est relativement plus grande ; elle est en effet voisine de 1 à 10 . On remarquera, cependant, qu'en valeur absolue, l'éventail des activités reste assez limité, 90 p. 100 des souches se classent dans l'intervalle 40-200. Sur ce milieu la distribution des activités apparaît unimodale et les souches d'origine Neufchâtel ne se distimguent pas du reste de la population (fig. 7).

Les activités protéasiques des mycéliums récoltés sur milieu Czapek-trypticase sont également bien groupées pour l'ensemble des souches, quelle que soit leur origine, et le caractère unimodal de cette distribution tend à confirmer l'homogénéité de la population (fig. 8).

Si l'on compare les activités protéasiques extracellulaires et intracellulaires des diverses souches, aucune relation entre les deux valeurs n'est constatée. Les rapports activité extracellulaire / activité intracellulaire sont, pour la plupart des souches, compris entre 1,5 et 4 et la figure 9 montre assez clairement toute absence de corrélation. On ne peut cependant tirer de cette observation aucune conclusion quant à la nature des protéases intra et extracellulaires. L'absence de relation entre la production des unes et des autres ne 
signifie pas nécessairement, par exemple, qu'il s'agit de systèmes enzymatiques fondamentalement différents. Pour établir l'identité ou la non identité de ces systèmes une étude approfondie de leurs caractères devra être effectuée.

Il n'est pas non plus observé, pour un milieu donné, de relation entre les productions d'enzyme extracellulaire et les $\mathrm{pH}$ de fin de culture ou les poids de mycélium. On peut en effet remarquer, sur le milieu Czapek-trypticase, que les valeurs de $\mathrm{pH}$ final et de poids de mycélium subissent des variations d'assez faible amplitude, beaucoup plus faible que celles constatées pour la production d'enzymes.

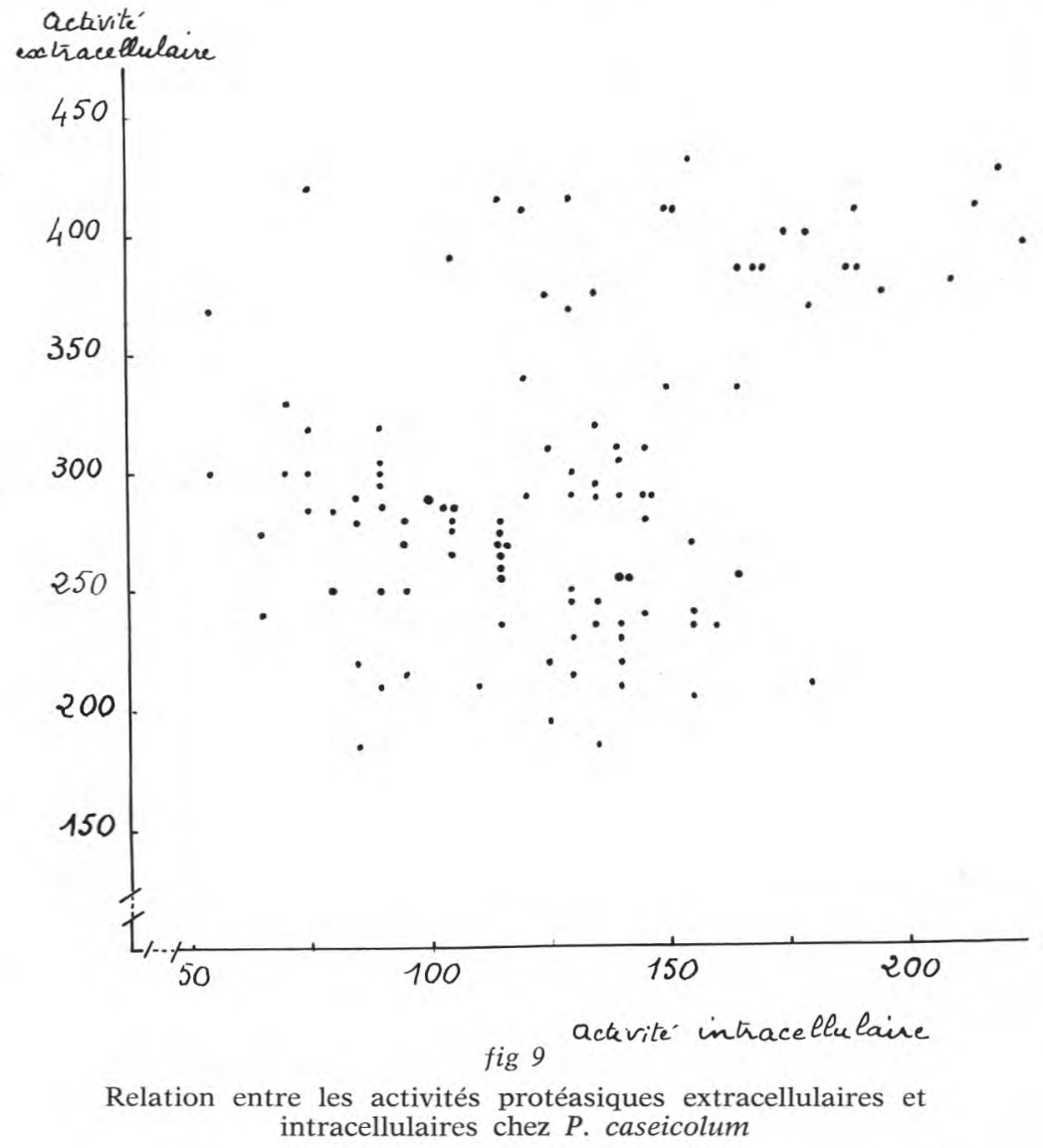

Activités protéasiques exprimées en $\mu \mathrm{g}$ de tyrosine par $\mathrm{ml}$ de préparation et par heure de digestion.

Conditions des essais

- Culture : milieu Czapek-trypticase, incubation 12 j à $20^{\circ} \mathrm{C}$, sans agitation, $\mathrm{pH} 6,5$.

- Détermination de l'activité : volume de préparation enzymaque $1 \mathrm{ml}$, temps de digestion $2 \mathrm{~h}$, température $40^{\circ} \mathrm{C}, \mathrm{pH} 6,0$. 


\section{Résumé et conclusions}

L'activité protéasique de $P$. caseicolum est considérée comme le principal responsable de la dégradation des matières azotées dans les fromages à pâtes molles de type Camembert, Carré de l'Est ou Brie, or cette activité reste encore insuffisamment connue. Ainsi, il est difficile de préciser l'aptitude réelle de l'espèce à la production d'enzymes protéolytiques car peu d'études de caractère général lui ont été consacrées.

La mise en place d'une collection de près de 110 souches de Penicillium caseicolum et la détermination de l'activité protéasique de ces souches dans des conditions de culture et de digestion définies a permis de caractériser l'espèce par son aptitude à la protéolyse.

Cette aptitude est liée à la composition du milieu de culture, notamment à la nature de la source d'azote, la présence d'azote peptidique constituant un facteur favorable de production. Sur un milieu contenant cette forme d'azote la production d'enzymes protéolytiques varie relativement peu d'une souche à l'autre ; la population étudiée présente donc, de ce point de vue, une assez grande homogénéité. Bien que faible, l'amplitude de variation observée dans la production d'enzymes paraît toutefois suffisante pour justifier une sélection des souches sur ce caractère en vue de leur utilisation en fabrications fromagères ou dans le domaine d'une production industrielle d'enzymes.

\section{Remerciements}

Nous remercions vivement $M$. Le Professeur Jacquet et MM. Desfleurs et Emery qui ont bien voulu mettre à notre disposition un certain nombre de souches de leurs collections.

\section{S u $\mathrm{m} \mathbf{m}$ a ry}

Aptitude of Penicillium caseicolum species for production of proteolytic enzyms

Penicillium caseicolum is the main liable for the degradation of proteins in soft cheeses with mouldy rind. Hovewer, its proteasic activity still remains insufficiently known.

A collection of nearly 110 strains from various origins has been constituted ; the favorable condition for production of proteolytic enzyms have been specified. The aptitude of strain for proteolytic activity has been estimated by means of culture during 12 days at $20^{\circ} \mathrm{C}$ (without any agitation). Two liquid culture media have been used, one was near of the Czapek-Dox's recipe (i), other has been modified by addition of a peptidic nitrogen source (ii). Proteolytic activity of the culture filtrate has been determined by digestion at 
pH 6 on a casein substract and then, by titration of 12 p. 100 trichloracetic acid soluble nitrogenous compounds according to Folin and Ciocalteu method.

Mycelium growth and enzym production are neatly more important on the medium (ii) but, on both media, and for the whole strains, results are reletively well grouped; they are situed on a activity range 40 to 200 for (i) and 210 to 450 for (ii). (Activities are expressed in $\mu \mathrm{g}$ tyrosin released per $\mathrm{ml}$ of preparation and per hour of digestion). So the studied population presented a pretty high homogeneity by its aptitude for protease production. Neverthelers, proteolytic activity is sufficiently different, from one strain to another for justifying a selection on this character in view of its utilization in cheese making.

\section{Références bibliographiques}

- Desfleurs (M.) (1966). - Contribution à la connaissance du genre Penicillium. Application à la fabrication de fromages à pâte molle et notamment du Camembert. Thèse Doctorat de $3^{\text {me }}$ Cycle, Faculté des Sciences de Caen.

- Dolezalek (J.) (1956). - Etude biochimique du Penicillium caseicolum. Industr. Alim. Agric., 73 (7-8), 535-539.

- Dox (A.W.) (1908). - Proteolytic changes in the ripening of Camembert cheese. U.S. Dept Agr. Bur. Anim. Ind. Bull., 109, 1-24.

- Folin (O.) and Ciocalteu (V.) (1927). - On tyrosine and tryptophane determination in proteins. J. Biol. Chem., 73, 627.

- Maze (P.) (1905). - Les microbes dans l'industrie fromagère. Ann. Inst. Pasteur, Paris, 19, 378-403, 481-493.

- Meyers and Knight (1958). - Studies on the nutrition of Penicillium roqueforti. Appl. Microbiol., 6 (3), 174-178.

- Proks (J.) and Cingrosova(K.) (1962). - The influence of Penicillium camemberti and Penicillium caseicolum on proteolytic and lipolytic changes in the ripening of Camembert cheese type. C.R. Cong. Int. Lait., vol. B, 442-448.

- RAPer (K.) and Thom (C.) (1949). - A Manual of the Penicillia. Baillière, Tindall and Cox ed., Londres.

- Sansonnetti (F.) (1930). - Sur les flores bactériennes et fongiques des caillés de lait. Le Lait, 10, 627.

- Sakaguchi (K. J.) and ABe (S.) (1957). - Atlas of microorganisms the Penicillia. Kanehara Shuppan Co, Tokyo.

- Tном (C.) (1906). - Fungi in cheese ripening : Camembert and Roquefort. U.S. Dept Agr. Bur, Anim. Ind. Bull., 82, 1-39.

- Thом (C.) (1909). - Camembert cheese problems in the United States. U.S. Dept Bur. Anim. Ind. Bull., 115, 1-54.

- Thom (C.) and RAPER (K.) (1945). - A Manual of the Aspergilli, Williams and Wilkins Co, Baltimore.

- Tsugo (T.), Matsuoka (H.) (1963). - Studies on the manufacture of semi soft white mould cheese ripened by Penicillium caseicolum. II. Qualities of proteases produced by Penicillium caseicolum. Jap. J. Zootech. Sci., 33 (6), 480-83 (in Dairy Sci. Abstr., 25, 1749).

Reçu pour publication en octobre 1970. 